\title{
The effect of irrelevant context on tachistoscopic recognition'
}

WILMA A. WINNICK AND PENNY BINSTOCK

QUEENS COLLEGE OF THE CITY UNIVERSITY OF NEW YORK

\begin{abstract}
Abstraet
It was hypothesized that the effect of irrelevant color cues on paired-associate learning might be generalizable to the tachistoscopic recognition situation. Words on colored backgrounds were learned by the free recall method to the criterion of one errorless trial. Half of these words on the same backgrounds and half on changed backgrounds were presented tachistoscopically along with unlearned control words on the colored backgrounds. Learned words on appropriate backgrounds had significantly lower thresholds than did those on inappropriate backgrounds; unlearned control words had significantly higher thresholds than did either of the types of learned words. Results were interpreted as supporting the hypothesis.
\end{abstract}

\section{Introduetion}

A number of recent experiments have shown variables important in verbal learning to be applicable to the word recognition situation. Thus, Gibson, Bishop, Schiff, \& Smith (1964) found tachistoscopic thresholds to be lower for pronounceable trigrams than they were for meaningful ones, while retention was better for meaningful than for pronounceable trigrams. Winnick \& Kressel (1965) studied abstractness-concreteness and frequency of usuage of words and found the latter to be of influence in paired-associate learning and free recall but not in tachistoscopic recognition. By contrast, the frequency variable affected recognition thresholds and paired-associate learning but showed no clear effect on free recall learning.

It seems reasonable to expect that additional variables found to affect verbal learning may similarly influence tachistoscopic word recognition. The variable manipulated in the present study is that of an irrelevant context. Tulving \& Gold (1963) studied the effect of a relevant context (the beginning words of a sentence) on tachistoscopic recognition. They found visual duration thresholds for words to decrease as the length of relevant and congruous contexts increased, but to increase as length of incongruous contexts increased.

The present experiment proposes to extend these findings by determining whether an irrelevant inappropriate context (colored background) will affect thresholds. The experiment parallels studies in learning (e.g., Weiss \& Margolius, 1954) that have found words learned on colored backgrounds to be better retained with the same colored backgrounds present as were present during learning than were words tested in the absence of the color cue. If a similar mechanism is present in word recognition, it might be predicted that words learned on colored backgrounds will be more readily perceived when presented tachistoscopically on the same colored backgrounds than when presented on colored backgrounds different from those used during learning.

\section{Method}

Experimental design: The context conditions were one source of "within Ss" variation; these conditions were: set words on same background, set words on different background, and control words. A second "within Ss" variable derived from the colors used: blue, green and red. The sole "between Ss" variable consisted of the three replications, identical except for the particular words used in the three context conditions, which were counterbalanced across the three replications.

Subjects: The Ss were 18 college students from an introductory psychology course, who participated in the experiment as part of a course requirement.

Apparatus: A Gerbrands mirror tachistoscope was used for the measurement of duration thresholds.

Materials: Red, blue and green construction paper was attached to $8-1 / 2$ by 11 in cards appropriate for the tachistoscope. Eighteen, eight-letter adjectives with a frequency of 10 to 20 times per million printed words were taken from the Thorndike-Lorge list (1944) on the basis of their being judged to have limited color associations. Words were centered on the cards using uppercase letters $3 / 16$ in in height from "Letraset" instant letters. The words were arbitrarily divided into three sets of six words, with each set presented under both experimental conditions and as controls, randomized across Ss to form three replications. Within a replication, every word appeared on a background of red, blue, and green, with colors equally represented under each condition for every $\mathrm{S}$. This procedure served the purpose of assuring that results would be independent of the word used, the color used, or an association between a color and a word.

Procedure: Preliminary learning used the free recall method, with Ss presented with the 12 experimental words against their colored backgrounds in a randomized order for $3 \mathrm{sec}$. each. Random-order presentations were continued with Ss required to recall the words to the criterion of one errorless trial. Standard free recall instructions were used, and no reference was made to the colors.

For the measurement of tachistoscopic thresholds, half of the learned words were presented in the tachistoscope against a background of the same color as was 
TABLE I

Mean Recognition Thresholds in Seconds for the Experimental

Conditions (context and color) in Three Replications and the ove rall Means

\begin{tabular}{|c|c|c|c|c|c|c|c|c|c|}
\hline & \multicolumn{3}{|c|}{ Same background } & \multicolumn{3}{|c|}{ Different background } & \multicolumn{3}{|c|}{ Control } \\
\hline & Red & Blue & Green & Red & Blue & Green & Red & Blue & Green \\
\hline $\begin{array}{l}\text { I. } \\
\text { II. } \\
\text { III. }\end{array}$ & $\begin{array}{l}.039 \\
.050 \\
.053\end{array}$ & $\begin{array}{l}.040 \\
.047 \\
.049 \\
\end{array}$ & $\begin{array}{l}.028 \\
.033 \\
.032 \\
\end{array}$ & $\begin{array}{l}.048 \\
.055 \\
.050 \\
\end{array}$ & $\begin{array}{l}.042 \\
.047 \\
.052 \\
\end{array}$ & $\begin{array}{l}.028 \\
.039 \\
.035\end{array}$ & $\begin{array}{l}.063 \\
.068 \\
.068 \\
\end{array}$ & $\begin{array}{l}.054 \\
.073 \\
.067 \\
\end{array}$ & $\begin{array}{l}.035 \\
.045 \\
.043 \\
\end{array}$ \\
\hline \multirow[t]{2}{*}{ Mean } & .047 & .045 & .031 & .051 & .047 & .034 & .066 & .065 & .041 \\
\hline & & .041 & & & .044 & & & .057 & \\
\hline
\end{tabular}

used previously, and half were seen on a background of one of the other two colors. This color change was varied from $S$ to $S$ in such a way that every alternative occurred once for each word with the colors equally represented for each S. Six control words were also presented against the three colored backgrounds. Standard instructions were used, and presentations were repeated at increasing exposure times beginning at .01 sec. until correct recognition was achieved.

\section{Results and Diseussion}

The means for the two contextual conditions and for the control words against each of the colors in each replication are shown in Table 1; shown here also are the overall means for the three types of words. Results were in the predicted direction, with learned words on the same background having the lowest thresholds and unlearned control words, the highest. The advantage of the words on the same background over those on different backgrounds was small but consistent in the three replications.

The results of the analysis of variance showed the differences among the three types of word contexts to be significant $(\mathrm{F}=27$; df 2,30; $\mathrm{p}<.001)$, as was the difference for the color dimension $(F=31$; df 2,30; $p<.001)$. Significance was not obtained for the replications; therefore, thresholds did not vary for the three groups of Ss, nor did they vary as a function of the particular words used in each condition. The sole significant interaction was found for the colors by conditions $(F=2.7 ;$ df 4,$60 ; p<.05)$, indicating that the relationship between the three types of presentations varied as a function of the color used. Specifically, the difference between learned words and control words was not as marked on the green background as on the blue and red.

Carrying the analysis further, $t$ tests were performed for the context variable. Thresholds for words presented on appropriate backgrounds were significantly lower than thresholds for words with changed backgrounds $(t=2.6 ;$ df $17 ; p<.01)$. There was, furthermore, a significant difference for learned words shown on different backgrounds compared with unlearned control words $(t=5.7 ;$ df $17 ; p<.001)$.

In view of the significant (though small) differences obtained in this experiment, the hypothesis that an irrelevant context factor present during learning can aid in subsequent tachistoscopic recognition appears to gain some support.

\section{References}

Gibson, E. J., Bishop, C. H., Schiff, W., \& Smith, J. Comparison of meaningfulness and pronunciability as grouping principles in the perception and retention of verbal material. J. exp. Psychol., 1964, 67, 173-182.

Thorndike. E. L., \& Lorge, I. The teacher's word book of 30,000 words. New York: Teachers' College, Columbia University, 1944.

Tulving, E., \& Gold, C. Stimulus information and contextual information as determinants of tachistoscopic recognition of words. J. exp. Psychol., 1963, 66, 319-327.

Weiss, W., \& Margolius, G. The effect of context stimuli on learning and retention. J. exp. Psychol., 1954, 48, 318-322.

Winnick, W. A., \& Kressel, K. Tachistoscopic recognition thresholds, paired associate learning and free recall as a function of abstractness-concreteness and word frequency. J. exp. Psychol., 1965 , in press.

\section{Note}

1. Based upon a thesis prepared by the second author to fulfill the requirements for the Master of Arts degree in Queens College of the City University of New York. This study was supported by a National Institute of Health grant (No. 10538-01) to the first author, entitled "Verbal learning and word recognition: some comparisons." 